\title{
WRISTBAND INOVATIF PENGHILANG KANTUK SAAT BELAJARDENGAN SENSOR DETAK JANTUNG BERBASIS IOT
}

\author{
AZKA ZAKIYYATUDDIN*, ALDO, DIAN AFIF, ADITIANTO RAMELAN \\ Prodi Fisika, \\ Fakultas Matematika dan Ilmu Pengetahuan Alam, Institut Teknologi Bandung \\ Jl. Ganeca No. 10, Lb. Siliwangi, Coblong, Kota Bandung, Jawa Barat 40132 \\ *email : azkakyokushin@gmail.com
}

\begin{abstract}
Abstrak.Salah satu permasalahan yang dihadapi oleh masyarakat Indonesia adalah keadaanmengantuk ketika melaksanakan berbagai aktivitas. Salah satunya seperti yang biasa dialami oleh pelajar ketika belajar atau ujian. Oleh karena itu, diperlukan sebuah alat untuk menghilangkan rasa kantuk pada saat menjalankan aktivitas. Kanmuru Wristband merupakan produk penghilang kantuk dengan basis teknologi sensor detak jantung. Kanmuru akan mendeteksi perubahan detak jantung pada pengguna, ketika detak jantung turun di bawah standar maka sensor akan mengkomunikasikannya melalui sistem nodeMCU kemudian meneruskannya ke aktuator vibration motor, buzzer dan/atau penyengat listrik sehingga akan ada getaran, suara nyaring, dan/atau sengatan listrik yang akan memberikan efek kejut kepada pengguna sesuai mode yang dipilih sehingga kantuk akan hilang. Selain itu, wristband ini dapat dihubungkan dengan android untuk memantau nilai BPM yang tercatat setiap waktunya, mengatur batasan BPM ngantuk, dan mengubah mode alat sesuai kebutuhan. Inovasi ini akan membantu mewujudkan SDGS poin ke-8 : Increasing labour productivity.

Kata Kunci: mode MCU, Kanmuru, sensor pulsa
\end{abstract}

\begin{abstract}
One of the problem that being faced by the people of Indonesia is the feeling of sleepy during their activity. One of the common example is students that feeling sleepy during their study or exam. Therefore, we need a device with the ability to deprive drowsiness. Kanmuru Wristband is one of the solution for that, with the technology of pulse sensor. Kanmuru will detect heartbeat rate difference of the user. When the heartrate is below standard value, it will communicate with nodeMCU and continue it to vibration motor, buzzer, and/or taser so there will be vibration, loud sound and/or electric shock depend on the mode that we choose. Then, it will stimulate shock effect that can clear drowsiness. Furthermore, the device can be connected to android to monitor the value of BPM from time to time, and adjust the lower limit of drowsiness. We can also set the working mode of Kanmuru. This innovation will help us to actualize point-8 of SDGS :Increasing labour productivity.
\end{abstract}

Keywords : nodeMCU, Kanmuru, Pulse Sensor

\section{Pendahuluan}

Panitia Sekolah dan perguruan tinggi adalah tempat bagi para pelajar untuk berkembang dalam lingkungan yang kondusif, dimana mereka dapat menambah pengetahuan, keterampilan, dan kemandirian dalam menentukan masa depannya. Dalam institusi pendidikan tersebut, pelajar dapat mempersiapkan dirinya untuk menjadi seseorang yang siap bekerja dan berkontribusi di masyarakat. Namun, demi menyiapkan hal tersebut tidak jarang seorang pelajar dituntut untuk menggunakan waktunya se-efektif mungkin agar tugas dan kegiatan lainnya dapat diselesaikan dengan baik. 
Namun, tidak semua pelajar mampu melakukan hal tersebut, beberapa akhirnya harus mengorbankan waktu istirahat mereka untuk menyelesaikan berbagai tugas sekolah. Sehingga, tidak sedikit pelajar Indonesia yang memiliki pola tidur yang tidak teratur, dan mengantuk selama kegiatan belajar mengajar berlangsung di sekolah.

Rasa kantuk adalah masalah yang cukup serius. Menurut penelitian, 50\% dari mahasiswa mengalami rasa kantuk di siang hari, dimana $36 \%$ dialami oleh siswa dan orang dewasa [1]. Setidaknya sekitar $60 \%$ mahasiswa melaporkan merasakan kantuk, lelah, dan lesu dalam 3 hari selama seminggu [2]. Rasa kantuk yang selalu datang tentu akan mengganggu aktivitas, dan berdampak pada produktivitas, kreativitas, kemampuan analisis dan stabilitas emosi menurun [3]. Di sisi lain, pelajar perlu mengikuti kegiatan belajar mengajar dengan baik sehingga ilmu yang disampaikan oleh guru dapat dipahami dengan baik. Karena ilmu itu sendiri dapat menentukan masa depan dari para pelajar serta kualitas SDM Indonesia di masa mendatang.

Dengan landasan permasalahan tersebut, penulis mencoba untuk menangani masalah kantuk tersebut dengan merancang sebuah alat penghilang kantuk. Alat tersebut dikemas dalam bentuk wristband dengan sistem sensor detak jantung yang terintegrasi dengan smartphone melalui fitur IoT (Internet of Things) yang diberi nama KANMURU. KANMURU akan mendeteksi rasa kantuk penggunanya dengan membaca detak jantung penggunanya. Kemudian akan memberikan respon berupa getaran, bunyi, dan sengatan listrik yang dapat memberi efek kejut sehingga menghilangkan rasa kantuk dengan cepat. Pembuatan KANMURU ini diharapkan dapat meningkatkan fokus dan prestasi para pelajar baik siswa maupun mahasiswa.

\section{Metode Penelitian}

Metode penelitian yang digunakan secara umum terdiri dari persiapan, pelaksanaan, dan evaluasi. Ketiga tahapan tersebut dirinci dalam metode-metode sebagai berikut :

\subsection{Persiapan}

Langkah awal yang peneliti lakukan dalam rangka menemukan masalahmasalah yang memerlukan penyelesaian adalah brainstorming. Hasil dari brainstorming yang peneliti lakukan yaitu banyaknya pelajar yang tertidur saat kegiatan belajar mengajar maupun saat ujian di kelas. Berdasarkan masalah sederhana yang terjadi dilingkungan terdekat peneliti sendiri, kami mencoba meneliti lebih dalam tentang permasalahan mengantuk yang dialami tidak pada waktu dan tempat yang tepat. Pencarian data dan fakta di lapangan kami lakukan dan kami menemukan dampak yang sangat besar dari kantuk yang dialami dan berdampak pada indeks prestasi para pelajar. Hal ini membuat peneliti tergerak untuk mencari solusi yang tepat sehingga masalah-masalah tersebut dapat diatasi. Diskusi yang kami lakukan menghasilkan sebuah ide untuk membuat alat yang dapat menghilangkan rasa kantuk, nyaman digunakan, dan mudah untuk dibawa kemana saja. Untuk mendapatkan rancangan dari teknologi yang akan peneliti kembangkan, maka peneliti juga melakukan studi pustaka lanjut untuk membuat rencana pengembangan alat. 


\subsection{Identifikasi dan Pemodelan Sistem}

Tahapan kedua yang peneliti lakukan adalah identifikasi pengembangan alat dengan merumuskan langkah-langkah yang sistematis dalam menciptakan luaran yang diharapkan sebagai solusi bagi permasalahan yang telah dirumuskan sebelumnya. Selain itu, dirancang pula suatu model penelitian dengan mempertimbangkan lama waktu yang diberikan hingga luaran yang diharapkan bisa direalisasikan dengan baik serta dapat dimanfaatkan secara langsung oleh pihak-pihak yang membutuhkan. Hasil dari analisis dan diskusi yang dilakukan pada tahapan ini digunakan sebagai acuan dalam merealisasikan rancangan alat.

\subsection{Perancangan dan Survei}

Tahap selanjutnya yang peneliti lakukan adalah membuat rancangan desain alat yang telah didiskusikan pada tahapan sebelumnya. Adapun desain yang peneliti rancang meliputi model rangkaian alat, komponen-komponen rangkaian, material yang akan digunakan, dan desain casing alat. Hasil dari perancangan ini terus dikaji hingga diperoleh rancangan akhir yang paling efektif dan tepat guna. Setelah diperoleh sebuah rancangan akhir yang paling efektif, selanjutnya peneliti melakukan survei kebutuhan alat dan bahan serta pemenuhan kebutuhan seperti komponen penunjang, bahan habis pakai, kebutuhan perjalanan, serta barang atau jasa pendukung lainnya.

\subsection{Realisasi Komponen Alat}

Tahapan ini merupakan tahap pembuatan alat yang telah dirancang sebelumnya. Pada tahap ini, peneliti menyusun komponen-komponen rangkaian barupa sensor detak jantung, mikrokontroler bertipe NodeMCU, dan aktuator berupa vibrationmotor, buzzer, dan penyengat listrik. Setelah rangkaian terpasang, selanjutnyapeneliti membuat program pembacaan data dari sensor detak jantung agar dapat diolah oleh mikrokontroler hingga dihasilkan output berupa getaran, bunyi, dan/atau sengatan listrik pada saat pengguna mengantuk. Kemudian dilakukan pembuatan casing alat agar menambah ketahanan kerja alat serta memiliki bentuk yang nyaman untuk dilihat dan dipakai.

\subsection{Pengujian Alat}

Setelah tahapan realisasi komponen alat selesai, maka dilakukan sejumlah pengujian pada alat untuk mengetahui efektifitas kerja dari alat yang telah peneliti buat. Adapun pengujian-pengujian yang peneliti lakukan diantaranya pengujian tingkat akurasi dari sensor detak jantung, pengujian frekuensi getar, intensitas bunyi, kuat arus listrik yang dialirkan, waktu kerja alat, serta pengujian langsung kepada pengguna secara langsung guna menyesuaikan kerja alat dengan keadaan di lapangan sehingga dapat dilakukan evaluasi dan penyempurnaan alat.

\subsection{Evaluasi dan Penyempurnaan Alat}

Setelah melakukan tahapan pengujian alat, dilakukan evaluasi terkait dengan kekurangan yang ada pada alat yang telah dibuat. Tahapan evaluasi ini 
difokuskan kepada efektifitas kerja alat untuk bisa memberikan efek kejut yang bisa menghilangkan kantuk namun tidak berbahaya bagi pengguna. Pada tahapan ini diperoleh informasi terkait dengan komponen-komponen pada alat yang harus ditingkatkan kinerjanya dalam upaya penyempurnaan keseluruhan alat. Hingga akhirnya, alat tersebut dapat digunakan sepenuhnya.

\section{Hasil dan Pembahasan}

Wristband inovatif bernama "KANMURU" bekerja dengan mengolah data detakjantung yang didapat melalui sensor detak jantung. Selain itu, alat ini memiliki fitur IoT dimana data detak jantung dapat tersimpan dan pengaturan alat dapat dilakukan melalui smartphone. Sistem kerja dari alat ini sendiri ditunjukan sebagai berikut :

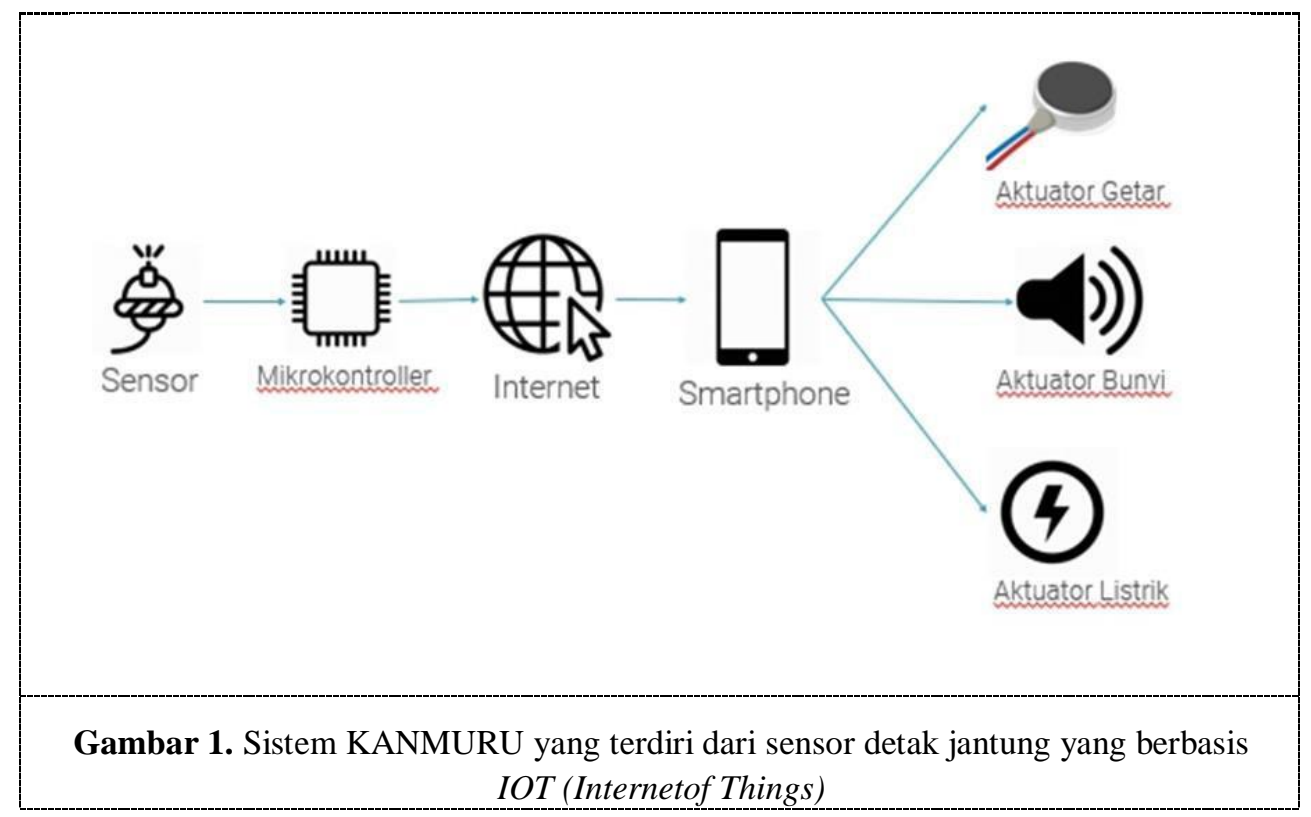

Dengan menerapkan sistem kerja tersebut, perancangan alat wristband inovatif dapat mulai dikerjakan.

\subsection{Implementasi Rancangan Hardware KANMURU}

Implementasi tahap pertama yaitu membuat rangkaian yang saling terhubung antara sensor detak jantung, mikrokontroler NodeMCU, baterai, dan aktuator berupa vibration motor, buzzer, dan listrik. Keseluruhan rangkaian ini dipasang pada breadboard untuk menguji rangkaian listrik yang dapat bekerja sesuai fungsi alat.Pemasangan rangkaian ini dilakukan untuk mendapatkan bentuk rangkaian yang paling tepat agar dapat dipasangkan dengan baik dalam bentuk wristband. 


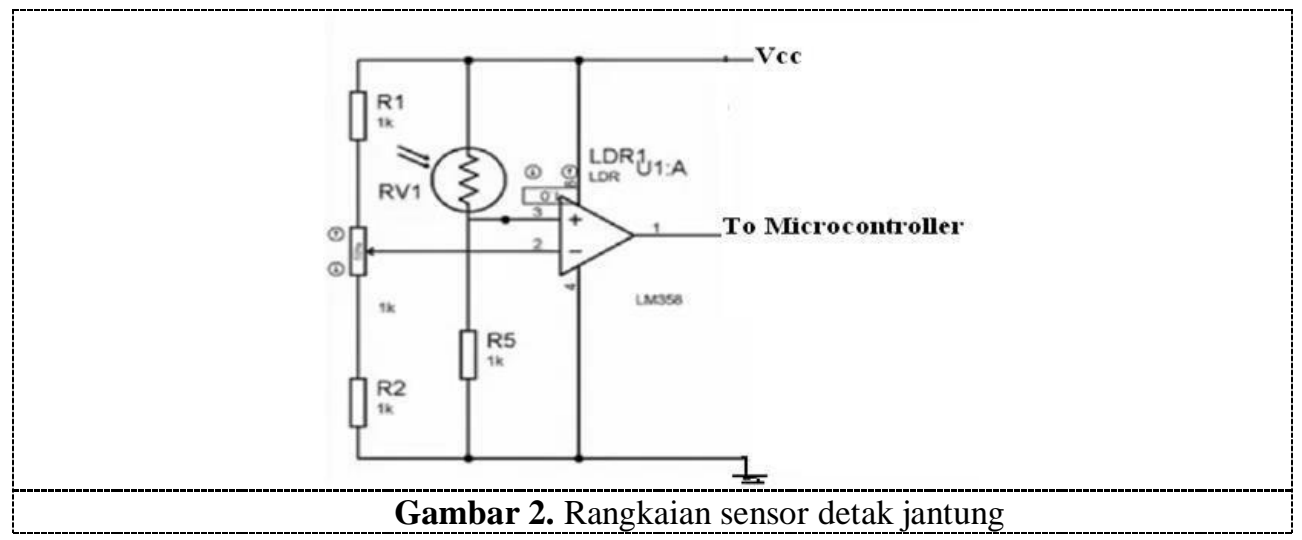

Tahap kedua dalam implementasi hardware ini adalah menambahkan komponen-komponen penunjang untuk KANMURU. Komponen penunjang ini berupa charger batrai, lampu LED, layar OLED (Organic Light Emitting Diode) dansebagainya. Hal ini dilakukan agar KANMURU dapat bekerja lebih baik dan menjadi penunjang komponen utama dari KANMURU yang sudah dipasang sebelumnya.

Implementasi tahap akhir yaitu menyusun komponen rangkaian ke dalam bentuk wristband. Pada tahap ini peneliti memasang rangkaian pada wristband yangterbuat dari bahan stretch cotton dan membuat rangkaian menjadi lebih compact untuk dipasang pada pengguna nantinya. Selanjutnya dibuat casing dengan menggunakan $3 D$ printing dengan material PLA+ sesuai dengan desain yang telah dibuat agar KANMURU terlihat lebih trendy dan dapat melindungi komponen-komponen alat yang ada di dalamnya.

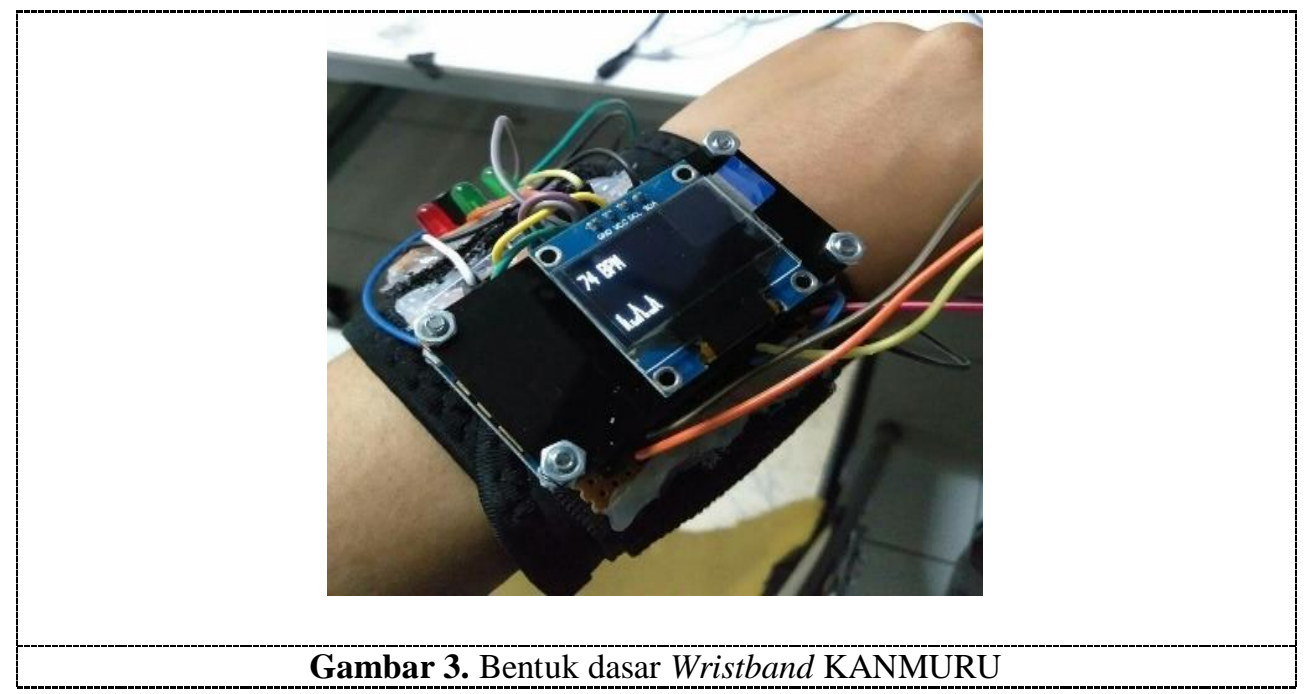



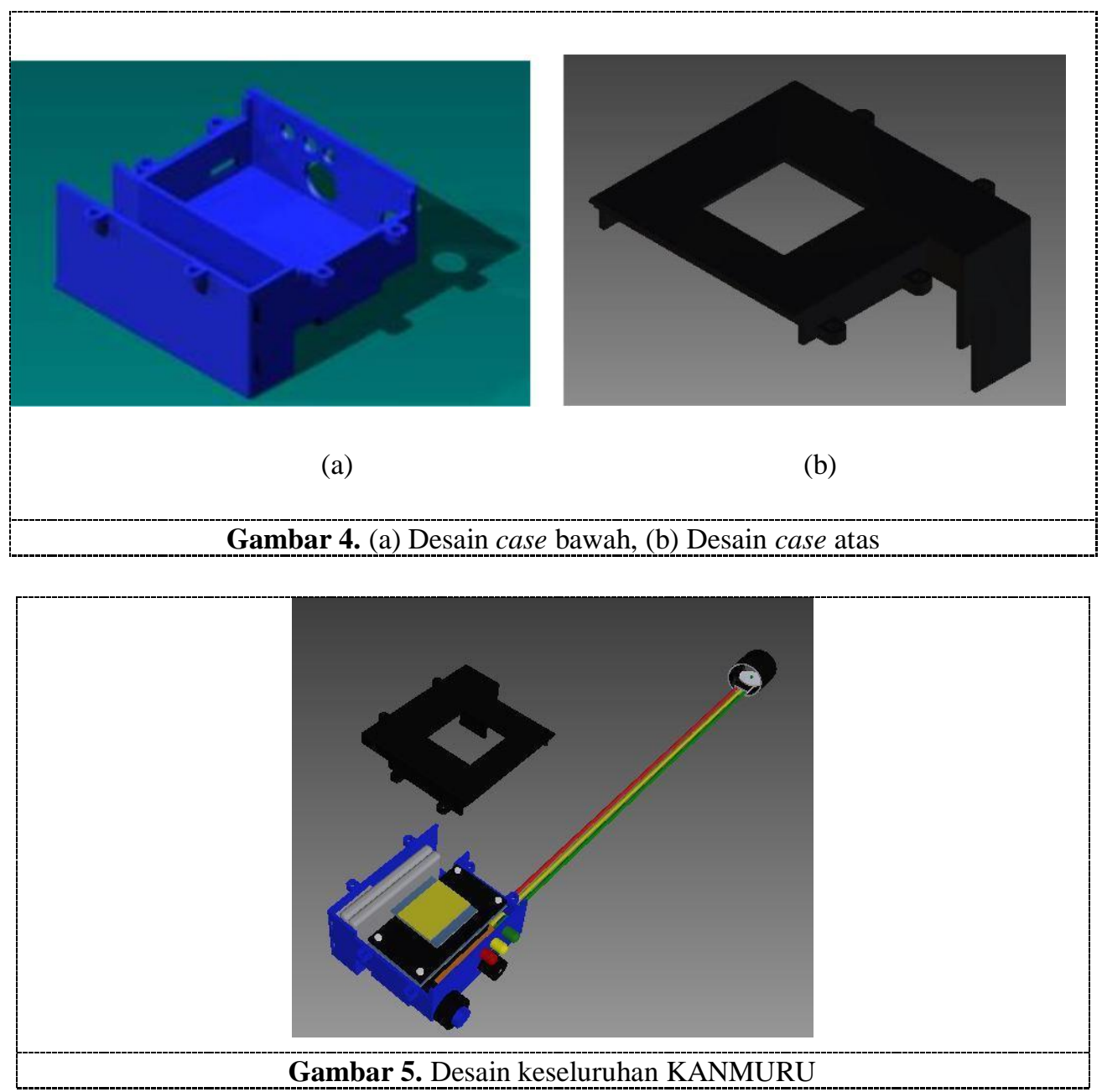

\subsection{Implementasi Rancangan Software KANMURU}

KANMURU akan menjadi alat yang utuh sebagai penghilang kantuk setelah diberikan sebuah program ke dalam mikrokontrolernya. Dalam tahapan ini peneliti membuat program untuk mikrokontroler NodeMCU menggunakan Arduino IDE agar mikrokontroler dapat membaca data dari sensor detak jantung kemudian mengubahnya ke dalam bentuk bpm (beat per minute) untuk dikirim ke sistem cloud agar dapat diakses melalui handphone pengguna. Agar dapat terhubungdengan handphone, peneliti menggunakan aplikasi blynk yang berfungsi sebagai platform fungsi IoT (Internet of Things) pada android. Aplikasi blynk ini diprogramagar dapat menampilkan data pembacaan sensor detak jantung yang telah diolah oleh mikrokontroler. Program ini dirancang untuk menampilkan dan menyimpan data detak jantung pengguna dalam bentuk grafik dan angka dalam satuan bpm(beat per minute). Selain itu, pada aplikasi ini pengguna dapat menginput angka bpm detak jantungnya dalam keadaan mengantuk (kalibrasi batas bpm sendiri) padaalat serta memilih mode aktuator yang diinginkanya. Aktuator terdiri dari tiga pilihan mode yaitu mode buzzer, ambiss, dan normal. Mode normal diaktifkan dengan menekan switch normal dari android yang ditandai dengan menyalanya lampu LED warna hijau pada alat. Ketika fungsi ini digunakan, KANMURU akan mengeluarkan output berupa getaran. Mode ambis ditandai 
aktif dengan menyalanya lampu LED berwarna kuning. Ketika mode ini digunakan, maka vibrator akan terus bergetar dan buzzer akan berbunyi ketika pengguna dideteksi mengantuk. Sedangkan mode buzzer ditandai dengan LED berwarna merah dan buzzer serta vibrator akan aktif hanya ketika pengguna dideteksi mengantuk.

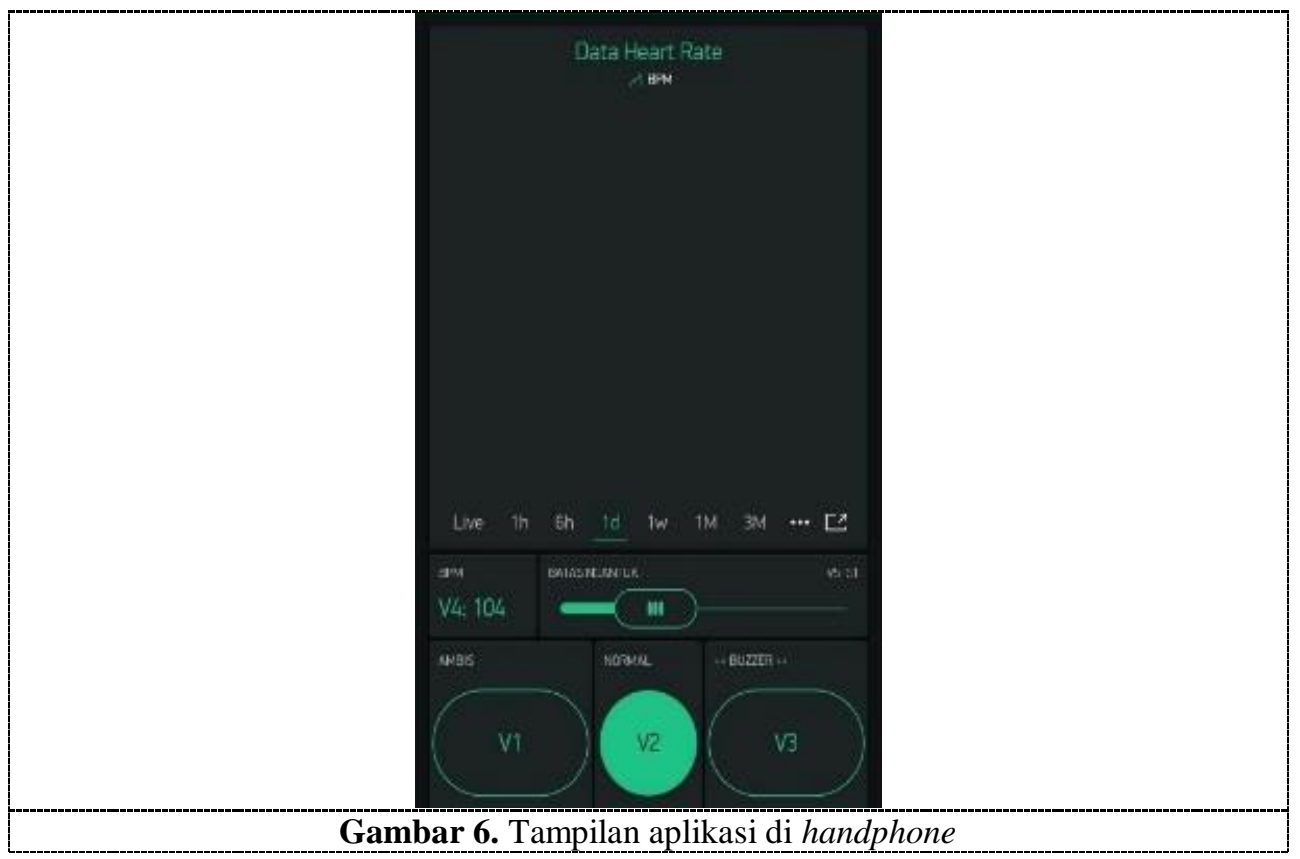

\subsection{Pengujian Sistem}

Pengujian sistem dilakukan untuk mengukur efektivitas kerja dari KANMURU. Adapun pengujian yang dilakukan yaitu pengujian terhadap ketepatan pembacaan sensor detak jantung, pengujian intensitas bunyi, pengujian frekuensi getar, pengujian kuat arus listrik pada alat setrum, serta pengujian terhadap perubahan detak jantung pengguna ketika KANMURU bekerja.

Uji galat sensor detak jantung merupakan pengujian terhadap data pembacaan detak jantung oleh alat. Pengujian ini dilakukan dengan membandingkan pembacaan KANMURU dengan pembacaan pada aplikasi Heart Rate Monitor pada handphone. Peneliti melakukan pengujian selama 5 menit dan mencatat setiap hasil pembacaan detak jantung dari KANMURU dan Heart Rate Monitor. Kemudian dilakukan perhitungan sehingga diperoleh rata-rata perbedaan pembacaan alat dengan smartphone sebesar 1,95\%. Berikut ini adalah tabel data pengujian alat : 
Tabel 1. Data pengujian error pembacaan BPM

\begin{tabular}{cccc}
\hline No. & Kanmuru (BPM) & Heart Rate Monitor (BPM) & Error $(\boldsymbol{\%})$ \\
\hline 1 & 69 & 68 & 1.470588 \\
2 & 69 & 70 & 1.428571 \\
3 & 74 & 72 & 2.777778 \\
4 & 74 & 74 & 0 \\
5 & 69 & 70 & 1.428571 \\
6 & 69 & 71 & 2.816901 \\
7 & 69 & 71 & 2.816901 \\
8 & 74 & 71 & 4.225352 \\
9 & 69 & 72 & 4.166667 \\
10 & 69 & 70 & 1.428571 \\
11 & 69 & 70 & 1.428571 \\
12 & 69 & 68 & 1.470588 \\
13 & 65 & 64 & 1.5625 \\
14 & 69 & 68 & 1.470588 \\
15 & 69 & 69 & 0 \\
16 & 65 & 66 & 1.515152 \\
17 & 69 & 68 & 1.470588 \\
18 & 69 & 68 & 1.470588 \\
19 & 80 & 84 & 4.761905 \\
20 & 69 & 70 & 1.428571 \\
& & Error rata-rata (\%) : & 1.956948 \\
\hline
\end{tabular}

Uji Aktuator KANMURU dilakukan untuk mengukur besarnya intensitas bunyi pada buzzer, frekuensi getar pada vibration motor, dan kuat arus listrik pada alat setrum. Intensitas bunyi buzzer diukur dengan aplikasi Sound Meter sehingga diperoleh nilai intensitas sebesar $76 \mathrm{~dB}$. Intensitas tersebut sudah cukup kencang untuk membangnkan manusia dari tidurnya [4]. Nilai frekuensi getar diperoleh sebesar 9000 RPM [5]. Kuat arus pada setruman sebesar 3 mA selama $2 \mathrm{~ms}$. Nilai ini sudah sesuai dengan teori yang diperoleh dari tahapan studi pustaka. Sehingga dapat disimpulkan bahwa KANMURU sudah dapat menghilangkan rasa kantuk saat bekerja dengan spesifikasi tersebut.

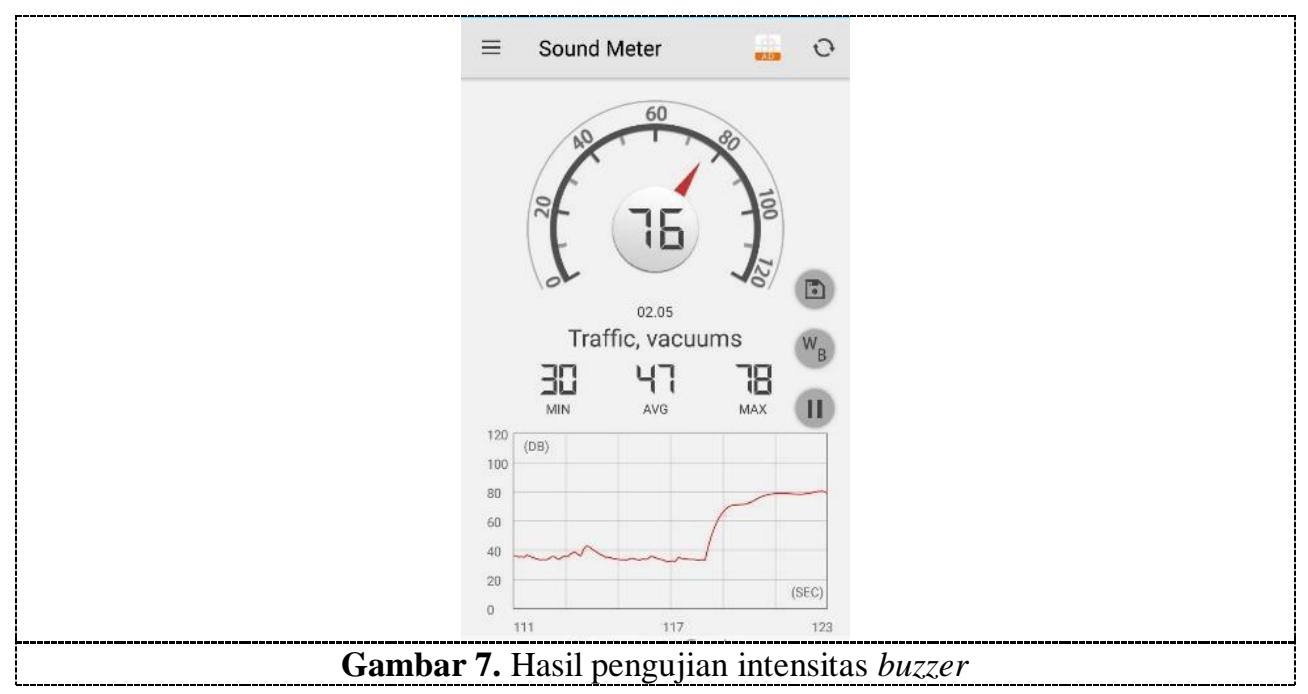


Uji efektifitas kerja alat dilakukan dengan mencoba menggunakan KANMURU secara langsung kepada pengguna kemudian mengukur perubahan detak jantung dari pengguna setelah alat bekerja. Perubahan detak jantung menandakan bahwa terjadi perubahan kondisi tubuh sehingga menghilangkan rasa kantuk. Efek kejut yang diberikan oleh KANMURU dapat membuat pengguna terbangun dari keadaan mengantuk yang dialaminya.

\section{Kesimpulan}

Wristband inovatif penghilang kantuk "KANMURU" berhasil direalisasikan dandapat bekerja cukup baik. KANMURU memiliki error pembacaan data bernilai $1.95 \%$. Fitur utama dalam kanmuru berupa pembacaan BPM, response actuator oleh vibration motor, buzzer, dan penyetrum dapat bekerja dengan baik. Selain itu,KANMURU juga sudah dapat terhubung melalui blynk dengan smartphone.

\section{Ucapan terima kasih}

Penulis mengucapkan terima kasih kepada berbagai pihak yang telah membantu dalam penulisan artikel ini. Terutama kepada Dr. Ir. Aditianto Ramelan atas bimbingannya dalam penelitian ini. Selain itu juga kepada KEMENRISTEKDIKTI yang telah mendanai penelitian alat ini.

\section{Daftar Pustaka}

1. H. Oginska, J. Pokorski, Fatigue and mood correlates of sleep length in three age-social goups: school children, students, and employees. ChronobiolInt. Vol. 23 Issue 6 (2006) p. 1317-1328.

2. American College Health Association . 2012. American College HealthAssociation: National College Health Assessment II Reference Group Executive Summary Spring 2012. Hanover, MD: American College Health Association;

3. Triamiyono, Heru. 2014. Upaya Mengatasi Rasa Kantuk di Kelas dalam ProsesBelajar Mahasiswa Taruna Akademi Maritim Djadajat. Jurnal Ilmiah WIDYAVolume 2.

4. Leger, Damien. 2017. Sound level intensity severely disrupts sleep in ventilatedICU patients throughout a $24-\mathrm{h}$ period: a preliminary $24-\mathrm{h}$ study of sleep stages and associated sound levels. PMC.

5. Precision Microdrives. 2014. "10mm Brushless Vibration Motor - 3mm Type". Dalam https://www.precisionmicrodrives.com/, diakses pada Sabtu, 2 Desember 2017 pukul 13.00.

6. Sturm, Anna. 2013. Effects of unconditioned stimulus intensity and fearextinction on subsequent sleep architecture in an afternoon nap. Max PlanckInstitute of Psychiatry, Munich, German. 